ISSN: 2277-3754

ISO 9001:2008 Certified

International Journal of Engineering and Innovative Technology (IJEIT)

Volume 11, Issue 5, November 2021

\title{
Effects of Compressor Blade Profile Change on Thermo-economic Performance of Gas Turbine
}

\author{
Jerry M. Asuo ${ }^{1}$, Barinaadaa T. Lebele-Alawa ${ }^{2}$, John I. Sodiki ${ }^{3}$ and Barinyima Nkoi ${ }^{4}$ \\ Department of Mechanical Engineering, Rivers State University, Port Harcourt, 5080, Rivers State, Nigeria
}

Hart [9] in his study has also established that the

\begin{abstract}
This study investigates the effects of variations in compressor blade profile on the thermo-economic performance of gas turbines. The compressor's thermo-economic performance was determined using data obtained from the power plant. The method used for the analysis was simplifying the compressor, combustion chamber, and turbine into control volumes. Each flow was analyzed based on exergy, economic, and exergy cost principles. As $\beta_{1}$ was increased, rotor blade deflection and diffusion were reduced while outlet velocity, stage efficiency, and pressure ratio increased. Pressure ratio increased by up to 20 percent when $\beta_{1}$ increased by $1^{0}$ and decreased by 7.5 percent when $\beta_{2}$ increased by $1^{0}$. Equipment cost, annualized cost and total capital investment, operation, and maintenance cost increased by 27.68 percent, 27.31 percent, and 22.86 percent as $\beta_{1}$ increased by $1^{0}$ while equipment cost, annualized cost and total capital investment, operation, and maintenance cost increased by 12.44 percent, 12.12 percent, and 12.45 percent as $\beta_{2}$ decreased by as much as $1^{0}$. Cost of exergy destruction, average unit cost of exergy input and average unit cost of exergy output increase by 2.64 percent, 2.62 percent, and 4.65 percent as $\beta_{1}$ increase by $1^{0}$. It was recommended that the gas turbine

filtration system be improved to suit the harsh environmental conditions of the area to reduce the amount of foulants on compressor blades. This will increase compressor life expectancy and efficiency, save operating and maintenance costs, and increase the reliability of the gas turbine to deliver maximum power. Furthermore, the research findings could serve as a useful reference for designers in selecting a reasonable compressor blade angle.
\end{abstract}

Keywords: Compressor, energy analysis, exergy costing, rotor blade angle, thermo-economics.

\section{INTRODUCTION}

Gas turbines are more appealing economically than other forms of power generation due to their low capital cost, high power-to-size ratio, high reliability, and flexibility in using a variety of fuels [21]. Because of their numerous advantages over other sources of power generation, they have become one of the most widely used technologies in power generation, and natural gas has become the primary operating fuel associated with their use. The Gas Turbine is an internal combustion engine with three main components: a compressor, a combustion chamber, and a turbine, and its operational behavior are determined by the efficiency of these components [6].

\footnotetext{
Manuscript received: 21 October 2021

Manuscript received in revised form: 20 November 2021

Manuscript accepted: 02 December 2021

Manuscript Available online: 15 December 2021
}

efficiency of the gas turbine depends on three main parameters: the aerodynamics efficiency of the compressor and turbine, the maximum cycle temperature and pressure ratio of the cycle among other parameters. Even under ideal operating conditions, a gas turbine's performance can deteriorate due to a variety of different environmental issues. Fouling, corrosion, erosion, and foreign object damage (FOD) because the blade profiles of the compressor and turbine to alter over time, resulting in performance loss [10]. Dust buildup on compressor blades modifies the air foil shape, reducing the compressor's efficiency and flow capacity by changing the angle of attack of the incoming air. Fouling that causes a 5\% loss in compressor flow capacity will result in a 2.5 percent drop in compressor efficiency and a $10 \%$ reduction in gas turbine power output [8]. To provide the requisite aerodynamic flow patterns, compressor blades are correctly shaped and positioned at optimal angles of incidence, and any change in blade geometry would have an impact on the blade intake or exit velocity triangles, potentially resulting in major performance changes. Changes in deviation at both rotor and stator blade rows and distortions in velocity diagrams at each compressor stage occur when the geometric dimensions of the air foils are changed under distorted conditions.

The importance of thermo-economics as a valuable tool in the design, evaluation, optimization, improvement, and cost analysis of thermal systems has been established in several research. Thermo-economic analysis is a system optimization tool that evaluates thermal energy systems using both the second law of thermodynamics (Exergy concept) and economic principles to provide designers with useful information for system improvement and costeffective operations [2][7][11]. The studies, however, showed no relationship between changes in compressor blade profile and thermo-economic variables. The current study focuses on the compressor and develops models that use structural theory of thermo-economics to establish a relationship between changes in compressor blade profiles and thermo-economic variables. The study also included models for entropy generation and capital cost estimations. The findings show that axial compressor losses, operating costs, and thermo-economic variables can be predicted during the design stage, which will aid operators and energy investors in making decisions about performance, sustainability, and economic feasibility. The study's primary objectives are as follows: Exergy analysis of an axial flow compressor of a gas turbine to assess its performance, 
ISSN: 2277-3754

ISO 9001:2008 Certified

International Journal of Engineering and Innovative Technology (IJEIT)

Volume 11, Issue 5, November 2021

evaluation of the quantities and cost of exergy destruction within the compressor due to variation in compressor blade profile and analysing the effect of variation in blade profile on non-exergy related costs of the compressor.

\section{MATERIALS AND METHODS}

\section{A. Description of Plant Investigated}

Figure 1 shows a schematic diagram of the system under investigation. A 180MW single shaft ALSTOM GT13E2 unit gas turbine power plant located in Afam, Rivers State, Nigeria. It uses natural gas with a low heating value $(\mathrm{LHV}=50,000 \mathrm{~kJ} / \mathrm{kg})$ and operates on the Brayton cycle. A 5 -stage turbine and a 21-stage axial compressor installed on the same shaft serve as the primary mechanical components, as does a combustion chamber between the compressor and the turbine. At a rotor speed of $3000 \mathrm{rpm}$, it has a maximum combustor temperature of $1368 \mathrm{~K}$, a pressure ratio of 16:1, and an exhaust flow of $528 \mathrm{~kg} / \mathrm{s}$.

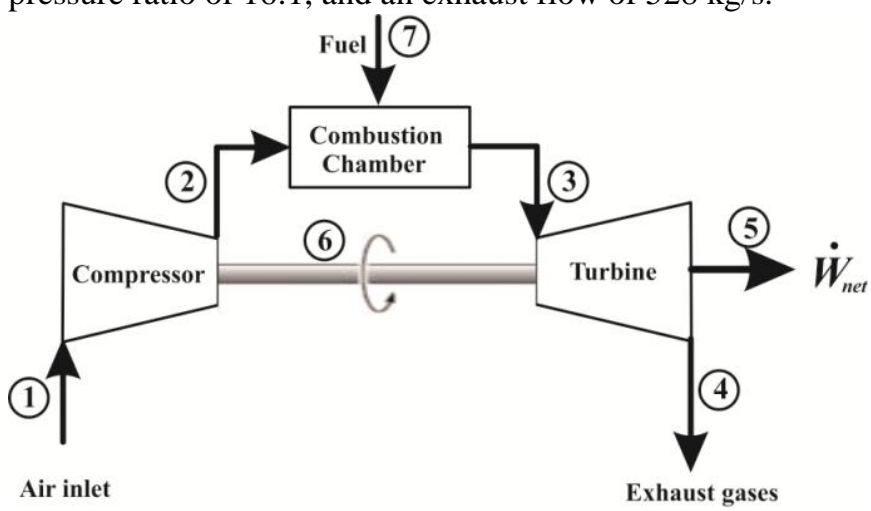

Fig. 1: Schematic Diagram of a Sigle Shaft Gas Turbine

\section{B. Equations and Analysis}

The analysis in this work was carried out using energy and thermo-economic models, with an emphasis on the compression process. An energy model was used to estimate the changes in pressure ratio caused by variations in compressor blade angles. The thermo-economic analysis consists of three steps. The first step was to perform an exergy analysis to determine the exergy flows and losses in the system components. The economic analysis step evaluates the monetary costs of the system's installation, operation, and maintenance. Exergy costing was the third step, which was used to estimate the exergy cost of each flow.

\section{Energy Model}

Considering both the total temperature rise across the compressor and the temperature rise across a stage in the case of multistage compressors. Isentropic total temperature at compressor exit:

$T_{2 s}=T_{1} \times r_{P}^{\frac{\gamma-1}{\gamma}}$

Actual total temperature rises across compressor:
$\Delta T_{a c t}=T_{2}-T_{1}=\frac{T_{1}\left(r_{P}^{\frac{\gamma-1}{\gamma}}-1\right)}{\eta_{i s}}$

Temperature rise across a stage is given by:

$T_{2}=T_{1}+\frac{\left(T_{2 s}-T_{1}\right)}{\eta_{i s}}$

In terms of blade angles, actual temperature rises across stage $\Delta T_{s t}$ is expressed according to (Gülen, 2019).

$\Delta T_{s t}=\frac{\lambda U V_{a}}{c_{p}}\left(\tan \beta_{1}-\tan \beta_{2}\right)=\frac{\lambda U_{b} \Delta V_{w}}{c_{p}}$

$\Delta V_{w}=V_{a}\left(\tan \beta_{1}-\tan \beta_{2}\right)$

From equations (1) and (3) we have.

$$
\begin{aligned}
& \frac{\Delta T_{a c t}}{\Delta T_{s t}}=T_{1}\left(\frac{r_{P}^{\frac{\gamma-1}{\gamma}}-1}{\eta_{i s}}\right) \times \frac{c_{p}}{\lambda U_{b} \Delta V_{w}}=N_{S} \\
& r_{p, c}^{0}=\left[1+N_{S}\left(\frac{\lambda \eta_{i s} U_{b} \Delta V_{w}}{c_{p} T_{01}}\right)\right]^{\frac{\gamma}{\gamma-1}} \\
& \therefore \quad r_{p, c}^{0}=\left[1+N_{S}\left(\frac{\eta_{i s} \Delta T_{s t}}{T_{01}}\right)\right]^{\frac{\gamma}{\gamma-1}}
\end{aligned}
$$

$r_{p, c}^{0}$ : Pressure ratio with respect to blade angle

$N_{S}:$ No of compressor stages

\section{Thermo-economic model}

Due to the limitations of energy analysis in thermal processes, exergy has been developed to account for energy losses due to irreversibility's within the system. The exergy component of fluid in a steady flow is given by the sum of the exergy's kinetic, potential, thermomechanical, and chemical components [5]. Exergy analysis allows for the evaluation of energy degradation, entropy degradation, and the loss of opportunities to do work during a process, and thus provides an alternative approach to power plant improvement. Because the processes are fixed in composition, the effects of kinetic and potential energy are 
ISSN: 2277-3754

ISO 9001:2008 Certified

International Journal of Engineering and Innovative Technology (IJEIT)

Volume 11, Issue 5, November 2021

negligible in this study. In the steady state, the velocity difference between the inlet and output is negligible, so the kinetic energy effect is ignored. Similarly, in industrial equipment such as axial compressors, the elevation difference at inlet and exit is insignificant at steady state; therefore potential energy consequences were neglected. As a result, as illustrated in the models below, exergy was defined as the maximum work taken from the stream when it was brought to the reference state by physical energy. Energy of products from compressor

$E_{2}=E_{p, c}=m_{a}\left[\left(h_{2}-h_{r e f}\right)-T_{r e f}\left\{\left(s_{2}^{0}-s_{r e f}^{0}\right)-R_{a} \ln \left(\frac{P_{2}}{P_{r e f}}\right)\right\}\right]$

Exergy of products from combustion chamber

$$
E_{3}=E_{p, c c}=m_{a}\left[\left(h_{3}-h_{r e f}\right)-T_{r e f}\left\{\left(s_{3}^{0}-s_{r e f}^{0}\right)-R_{a} \ln \left(\frac{P_{3}}{P_{r e f}}\right)\right\}\right]
$$

Exergy of products from turbine

$E_{4}=E_{p, t}=m_{a}\left[\left(h_{4}-h_{r e f}\right)-T_{r e f}\left\{\left(s_{4}^{0}-s_{r e f}^{0}\right)-R_{a} \ln \left(\frac{P_{4}}{P_{r e f}}\right)\right\}\right]$

Network output from turbine

$$
E_{5}=W_{N E T}
$$

Exergy of work input to compressor

$$
E_{6}=E_{w, c}=m_{a} \frac{\left[\left(h_{2}-h_{1}\right)\right]}{\eta_{i s}}
$$

Exergy destruction rate in compressor

$I_{c}^{0}=m_{a} T_{r e f}\left[\left(s_{2}^{0}-s_{r e f}^{0}\right)-R_{a} \ln \left(\frac{P_{2}}{P_{r e f}}\right)\right]$

Exergetic efficiency of compressor: $\varepsilon_{c}$

$$
\varepsilon_{c}=\frac{E_{p, c}}{E_{w, c}} \times 100
$$

\section{Economic model}

The compressor equipment cost $P E C_{c}^{0}$ is expressed (16).

$$
P E C_{c}^{0}=\left[\frac{71.1 m_{a}}{0.9-\eta_{i s}}\right]\left[r_{p, c}^{0}\right] \ln \left[r_{p, c}^{0}\right]
$$

Annualization cost of compressor $\left(C_{c}^{0}\right)$ was given by equation (17) and in this study all investment cost values are expressed in terms of the Dollar (\$).

$$
C_{c}^{0}=P W_{c}^{0} \times C R F
$$

Total capital investment, operation \& maintenance cost of compressor, $Z_{c}^{0}$ is expressed according to equation (18) as follows:

$Z_{c}^{0}=\frac{\phi \times C_{c}^{0}}{3600 \times N}$

\section{E. Exergy cost model}

Cost flow rates per unit exergy of all plant components were considered to determine the compressor's cost flow rate per unit exergy. Three sets of non-linear equations were formulated and solved to determine the cost flow rates for all the streams in the entire plant using Specific-Exergy Costing (SPECO) as proposed by [3],[15]. Assumptions were made as follows: Cost of air entering the compressor, $C_{1}^{0}=0$; At states 3 and 4 , the cost rate per unit exergy is the same and the cost rate per unit exergy in state 5 equals the cost rate per unit exergy in state 6 .

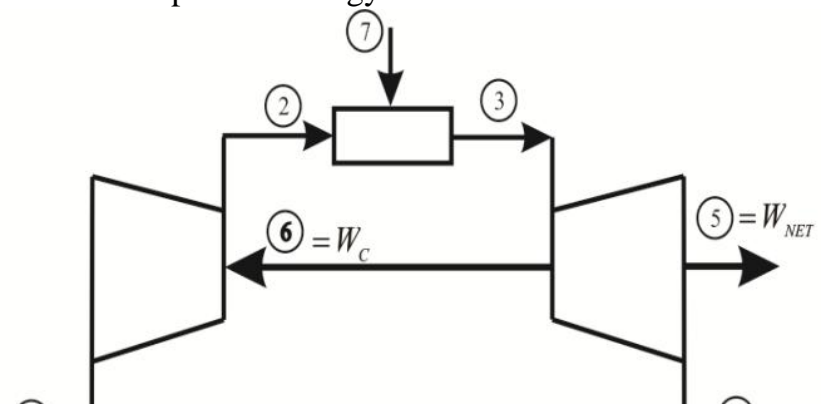

Fig. 2: Control Volume for Generalized Cost Balance

According to [7], the generalized cost balance equation for the entire plant was expressed as follows:

$\sum\left(c_{e}^{0} E_{e}\right)_{k}+c_{w, k}^{0} W_{k}=c_{q, k}^{0} E_{q, k}+\sum\left(c_{j}^{0} E_{j}\right)_{k}+Z_{k}^{0}$

$C_{j}^{0}=c_{j}^{0} E_{j}$

\section{Compressor:}

$C_{1}^{0}=0$

$C_{2}^{0}=C_{1}^{0}+C_{6}^{0}+Z_{c}^{0}$

\section{Combustion chamber:}

$C_{3}^{0}=C_{2}^{0}+C_{7}^{0}+Z_{c c}^{0}$ 
ISSN: 2277-3754

ISO 9001:2008 Certified

International Journal of Engineering and Innovative Technology (IJEIT)

Volume 11, Issue 5, November 2021

The cost rate of fuel $C_{f}=C_{7}$ was obtained from [19][20]:

$C_{f}=c_{f} m_{f} L H V$

$c_{f}:$ Fuel cost per energy unit $=0.004 \$ / \mathrm{MJ}[24]$

$m_{f}:$ Mass flow rate of fuel (natural gas)

$L H V$ : Lower heating value of fuel

Turbine:

$C_{4}^{0}+C_{5}^{0}+C_{6}^{0}=C_{3}^{0}+Z_{t}^{0}$

The following auxiliary equations were derived from cost balance equations using the F-Principle and P-Principle, as stated below:

$\frac{C_{3}^{0}}{E_{3}}=\frac{C_{4}^{0}}{E_{4}}$

Similarly,

$$
\frac{C_{5}^{0}}{W_{N E T}}=\frac{C_{6}^{0}}{W_{c}}
$$

The cost flows from the general cost-balance equation for the compressor, combustion chamber, and turbine form a set of linear equations that can be arranged into a matrix form and solved to determine the values of $C_{1}^{0}, C_{2}^{0}, C_{3}^{0}, C_{4}^{0}, C_{5}^{0}, C_{6}^{0}$ and $C_{7}^{0}$ as shown below:

$$
\left\{\begin{array}{ccccccc}
1 & 0 & 0 & 0 & 0 & 0 & 0 \\
-1 & 1 & 0 & 0 & 0 & -1 & 0 \\
0 & 0 & 0 & 0 & \frac{1}{E_{5}} & -\frac{1}{E_{6}} & 0 \\
0 & -1 & 1 & 0 & 0 & 0 & -1 \\
0 & 0 & \frac{1}{E_{3}} & -\frac{1}{E_{4}} & 0 & 0 & 0 \\
0 & 0 & 0 & 0 & 0 & 0 & 1 \\
0 & 0 & -1 & 1 & 1 & 1 & 0
\end{array}\right\}\left\{\begin{array}{l}
C_{1}^{0} \\
C_{2}^{0} \\
C_{3}^{0} \\
C_{4}^{0} \\
C_{5}^{0} \\
C_{6}^{0} \\
C_{7}^{0}
\end{array}\right\}=\left\{\begin{array}{c}
0 \\
Z_{c}^{0} \\
0 \\
Z_{c c}^{0} \\
0 \\
c_{f} m_{f} L H V \\
Z_{t}^{0}
\end{array}\right\}
$$

\section{Average cost per unit of exergy input and output}

Average costs per exergy unit of work input and product for the compressor was expressed as follows:

$$
\begin{gathered}
c_{w, c}^{0}=\frac{C_{w, c}^{0}}{E_{w, c}}=\frac{C_{1}^{0}+C_{6}^{0}}{E_{1}+E_{6}} \\
c_{p, c}^{0}=\frac{C_{p . c}^{0}}{E_{p, c}}=\frac{C_{2}^{0}-C_{1}^{0}}{E_{2}-E_{1}}
\end{gathered}
$$

\section{Cost of exergy destruction}

The cost rate associated with exergy destruction was estimated as follows:

$$
C_{d, c}=c_{p, c} m_{a} T_{r e f}\left[\left(s_{2}^{0}-s_{r e f}^{0}\right)-R_{a} \ln \left(\frac{P_{2}}{P_{r e f}}\right)\right]
$$

\section{Relative cost difference: $\gamma_{c}^{0}$}

The relative cost difference is a performance index that shows the rate of increase in average cost per exergy unit of work input and product in the compressor, and it was stated in this study according to [1].

$\gamma_{c}^{0}=\frac{c_{p, c}^{0}-c_{w, c}^{0}}{c_{w, c}^{0}}$

\section{Exergo-economic factor: $f_{c}^{0}$}

This compares the two cost sources that contribute to the cost increase, which are the cost of work input to the compressor and the cost of products. The cost is divided into two categories: non-exergy costs (capital investment and operation and maintenance costs) and exergy costs (cost of exergy destruction and exergy losses). Equation (32) was used to express the exergo-economic factor.

$$
f_{c}^{0}=\frac{Z_{c}^{0}}{Z_{c}^{0}+C_{d, c}^{0}}
$$

\section{RESULTS AND DISCUSSIONS}

A. Results of variation of blade inlet angle at constant blade outlet angle

Graph of rotor blade angle against equipment cost is plotted and shown in Figures 3. The cost of equipment rises as $\beta_{l}$ increases. According to [14], increasing an air compressor's isentropic efficiency raises the investment cost. According to the current study, $\beta_{l}$ increases with pressure ratio and isentropic efficiency, resulting in an increase in compressor equipment cost. According to Figure 3 , the cost of equipment increased by 27.76 percent as the rotor blade inlet angle increased by $1^{0}$. Graph of rotor blade angle against annualized cost is shown in Figure 4. The annualized cost rises by 27.83 percent as $\beta_{1}$ rises by $1^{0}$ due to an increase in the average cost per unit of exergy input, pressure ratio, and mass flow rate. 
ISSN: 2277-3754

ISO 9001:2008 Certified

International Journal of Engineering and Innovative Technology (IJEIT)

Volume 11, Issue 5, November 2021

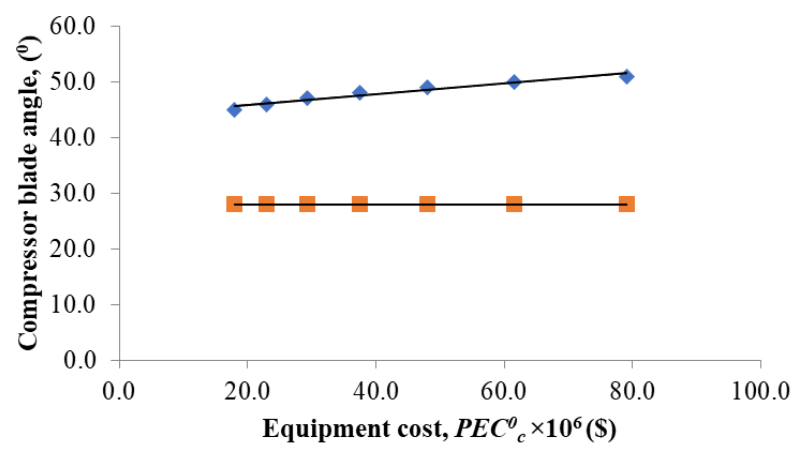

Fig. 3: Graph of Compressor Blade Angle Vs Equipment Cost

Their research shows that as the pressure ratio increases with $\beta_{1}$, the mass flow rate decreases nonlinearly for compressible gas flows.

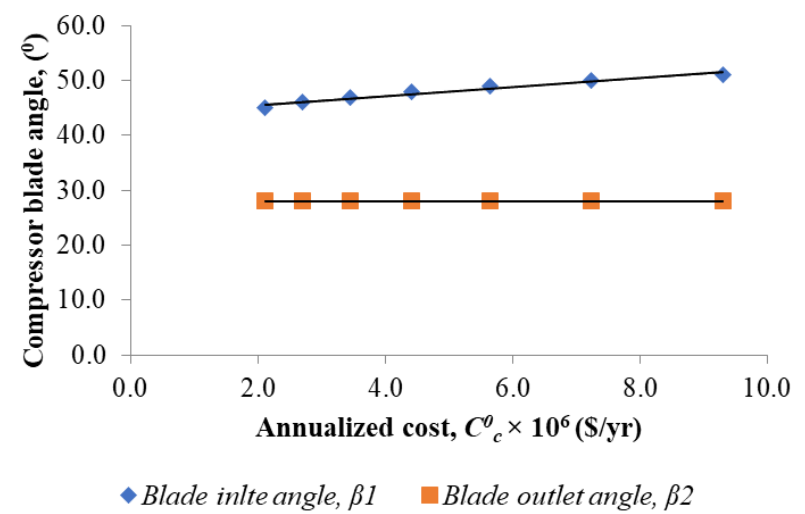

Fig 4: Graph of Compressor Blade angle Vs Annualized Cost

Figure 5 shows a graph of rotor blade angle against total investment, operating, and maintenance costs. In their research, [14] discovered that the pressure ratio rises with the compressor's investment cost. The pressure ratio increases as the rotor blade inlet angle increases, resulting in increased capital investment, operating, and maintenance costs. Total capital investment, operation, and maintenance costs increased by 27.66 percent as the rotor blade inlet angle increased by $1^{0}$. According to [19], the total capital investment, operation, and maintenance cost of an air compressor is determined by the pressure ratio; thus, reducing $\beta_{1}$ can reduce total investment cost value. The results of a multi-objective optimization using the Pareto Frontier to determine the best among the optimal design parameters of an air compressor show that the total cost of the compressor increases moderately as the pressure ratio and exergetic efficiency increase. The cost of exergy destruction rises as $\beta_{1}$ and pressure ratio increase. Figure 6 shows a graph of rotor blade angle versus cost of exergy destruction. As the pressure ratio increases during the compression process, more work is required, resulting in an increase in irreversibility's, entropy generation, and exergy destruction, and thus an increase in the cost of exergy destruction.

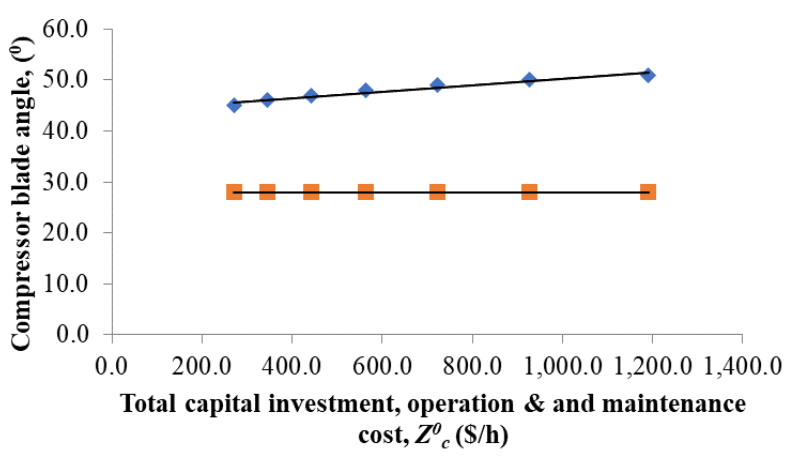

- Blade inlet angle, $\beta 1 \quad$ Blade outlet angle, $\beta 2$

Fig. 5: Graph of Compressor Blade Angle Vs Total Capital Investment, Operation and Maintenance Cost

The findings of [13] and [22] are consistent with the current study. Their findings show that exergy destruction increases with pressure ratio due to an increase in the rate of entropy generation. According to Figure 6, the cost of exergy destruction increased by 2.69 percent per degree increase in $\beta_{1}$.

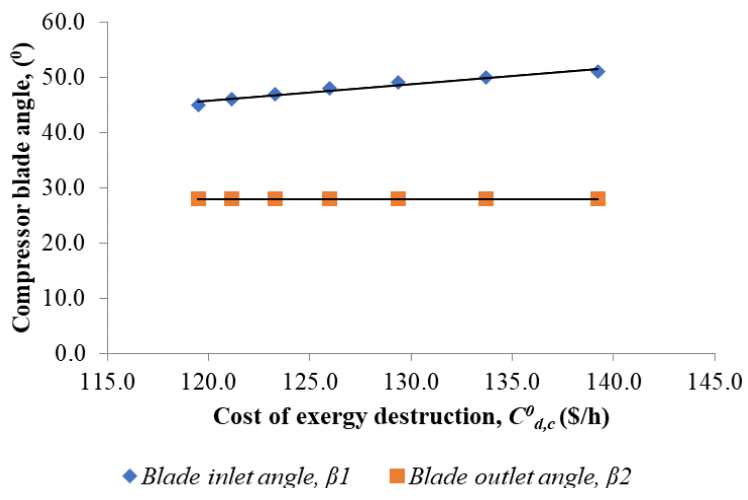

Fig. 6: Graph of Compressor Blade Angle Vs Cost of Exergy Destruction

Figure 7 show graph of variation of rotor blade angle versus average cost per unit of exergy input. The average cost per unit of exergy input rises as $\beta_{1}$ increases. This is because increasing the pressure ratio necessitates additional work and cost, resulting in an increase in the cost of exergy input to the compressor. According to Figure 6, the average cost per unit of exergy input increased by 2.80 percent as $\beta_{1}$ increased by $1^{0}$. Valencia et. al. (2019) investigated the relationship between pressure ratio and exergy input. Their findings show that as the pressure ratio increases, so does the cost of fuel per unit exergy input. Figure 8 shows a graph of rotor blade angle against average cost per unit of exergy output. Due to an increase in the pressure ratio, the average cost of unit exergy output rises as $\beta_{1}$ rises. According to the findings of [11], as the pressure ratio and turbine inlet temperature rise, the average cost per unit of exergy of products falls to a minimum and then begins to rise as the pressure ratio and turbine inlet temperature rise further. As $\beta_{1}$ increased by $1^{0}$, the average cost per unit of exergy increased by 5.14 percent. 
ISSN: 2277-3754

ISO 9001:2008 Certified

International Journal of Engineering and Innovative Technology (IJEIT)

Volume 11, Issue 5, November 2021

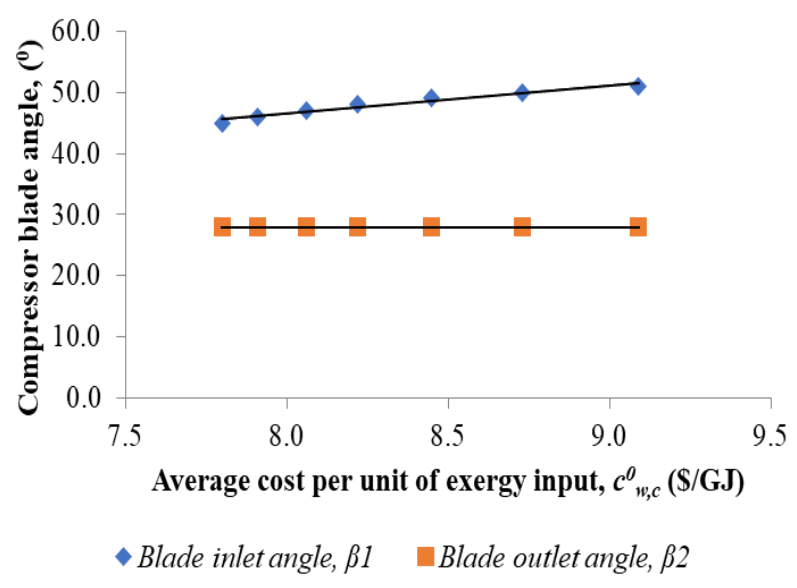

Fig 7: Graph of Compressor Blade Angle Vs Average Cost per unit of exergy input

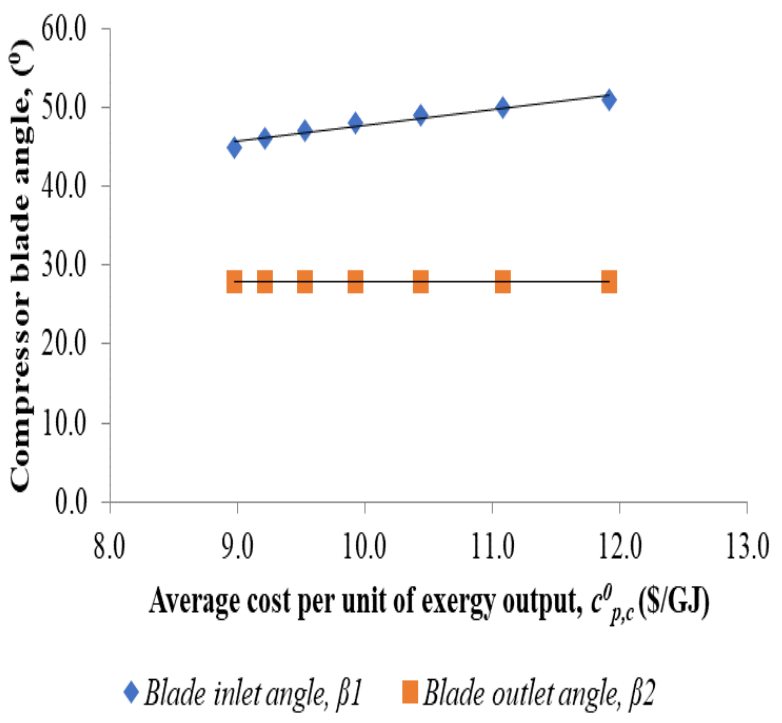

Fig 8: Graph of Compressor Blade Angles Vs Average Cost per Unit of Exergy Output

Figure 9 illustrates a graph of rotor blade angle vs relative cost difference. As $\beta_{1}$ and pressure ratio increase, the relative cost difference increases. This result is like that of [17], who found that increasing the pressure ratio from 6 to 8 the relative cost difference increased by 15 percent. In the current study, the pressure ratio increased by $13.68 \%$ as $\beta_{1}$ increased by $1^{0}$. Graph of rotor blade angle against exergo-economic factor is plotted and shown Figure 10. According to the findings, the exergo-economic factor rises when $\beta_{1}$ rises due to an increase in the pressure ratio. [17] Found that the exergo-economic factor increases with compressor pressure ratio but decreases with combustion chamber in their study on integrated biomass gasification combined cycle plant for small scale power. [18] found that the exergo-economic factor increases as the pressure ratio rises. As $\beta_{1}$ increased by $1^{0}$, the exergo-economic factor increased by 5.56 percent.

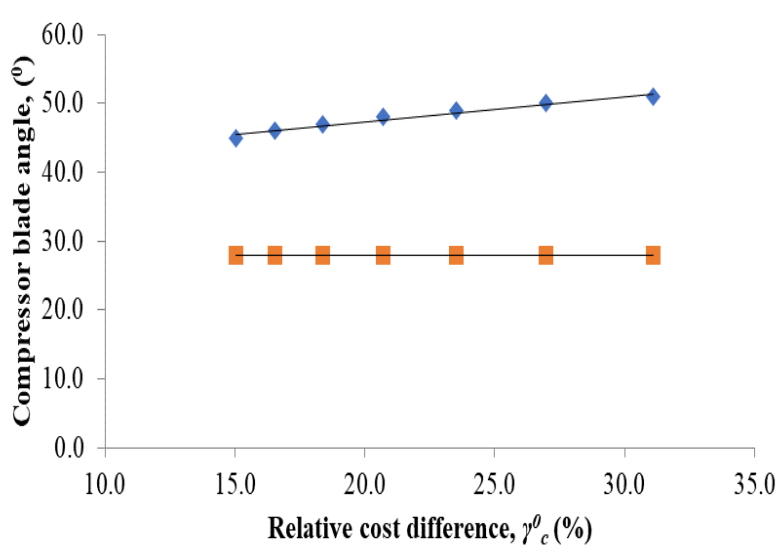

- Blade inletangle, $\beta 1 \quad$ Blade outlet angle, $\beta 2$

Fig 9: Graph of Compressor Blade Angle Vs Relative Cost Difference

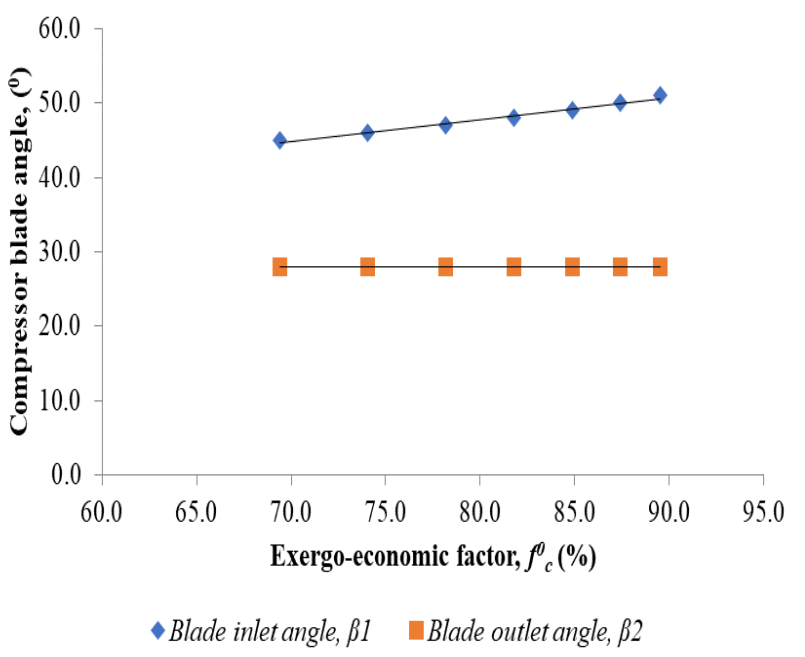

Fig 10: Graph of Compressor Blade Angle Vs Exergo-economic Factor

\section{Results of variation of blade outlet angle at constant blade inlet angle}

Figure 11 represents a graph of rotor blade angle versus equipment cost. The graph shows that as $\beta_{2}$ decreases, the cost of the equipment increases. The equipment cost increased by 12.44 percent from $\$ 20.0111$ to $\$ 22.5106$ as the $\beta_{2}$ decreased by $1^{0}$ from $27^{0}$ to $26^{0}$. By decreasing $\beta_{2}$, the stage's loading capability and pressure ratio are increased. The pressure ratio rises as the $\beta_{2}$ decreases with a constant $\beta_{1}$, increasing equipment costs. According to [16], the cost of equipment increased moderately as the pressure ratio increased. The graph of rotor blade angles against annualized cost is shown in Figure 12. The annualized cost increased by 12.50 percent as $\beta_{2}$ decreased by $1^{0}$. When compared to Figure 5 , the total investment, operation and maintenance costs, pressure ratio, and mass 
ISSN: 2277-3754

ISO 9001:2008 Certified

International Journal of Engineering and Innovative Technology (IJEIT)

Volume 11, Issue 5, November 2021

flow rate all increase when $\beta_{2}$ decreases, resulting in an increase in the equipment's annualized cost.

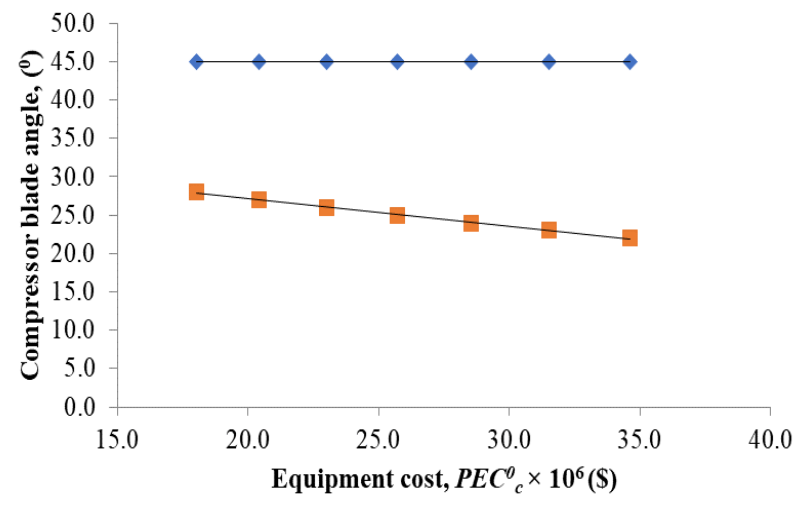

- Blade inlet angle, $\beta 1 \quad$ Blade outlet angle, $\beta 2$

Fig 11: Graph of Compressor Blade Angle Vs Equipment Cost

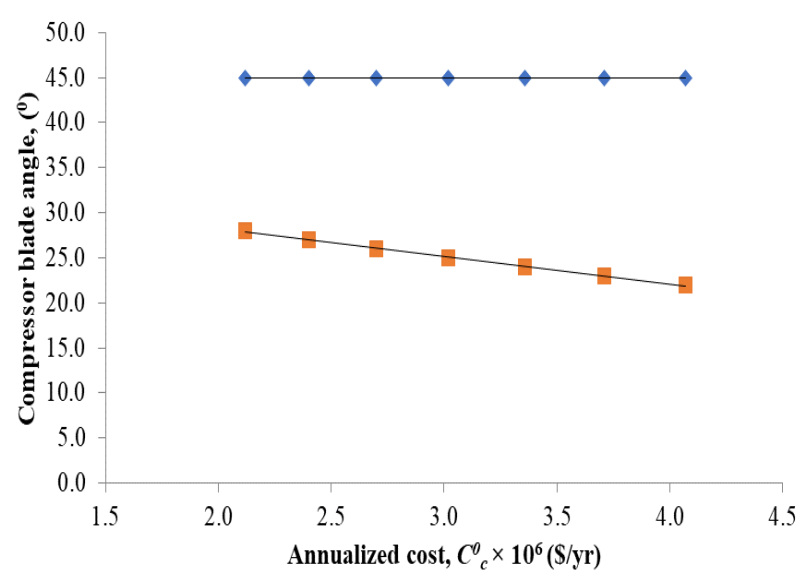

Fig 12: Graph of Compressor Blade angle Vs Annualized Cost

Figure 13 represents a graph of rotor blade angle versus total investment, operation, and maintenance costs. As $\beta_{2}$ of a centrifugal compressor decreases, so does its head and efficiency [4].

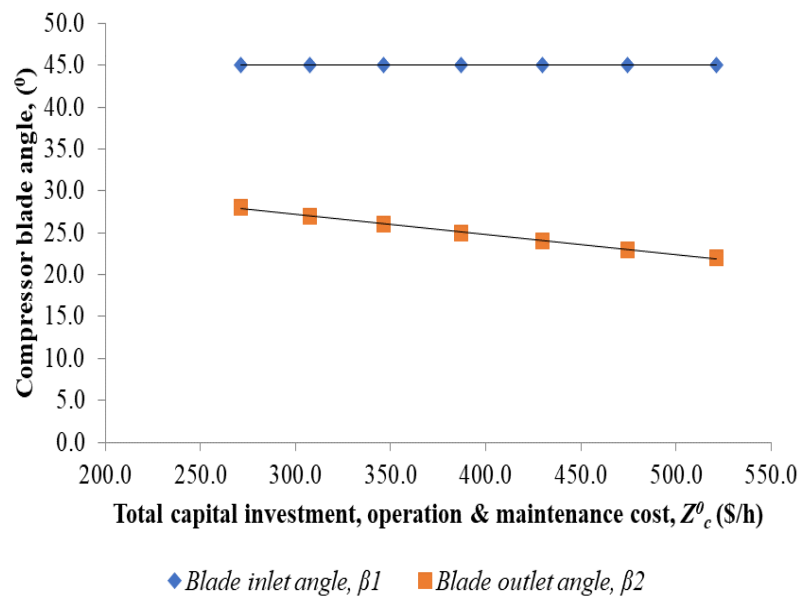

Fig 13: Graph of Compressor Blade Angle Vs Total Capital Investment, Operation and Maintenance Cost
Like axial centrifugal compressors, the efficiency and pressure ratio of an air compressor increase as $\beta_{2}$ decreases because higher pressures require additional work input. According to the graph, as $\beta_{2}$ decreases, the overall investment, operating, and maintenance costs rise. As $\beta_{2}$ decreases by $1^{0}$, the total capital investment, operating, and maintenance costs rise by 12.56 percent. The rate of exergy destruction determines the cost of exergy destruction [19]. The graph of rotor blade angle against cost of exergy destruction is shown in Figure 14. The cost of exergy destruction rises as $\beta_{2}$ decreases. The rate of entropy generation increases as $\beta_{2}$ is reduced, resulting in an increase in exergy destruction and pressure ratio. As $\beta_{2}$

decreased by $1^{0}$, the cost of exergy destruction increased by 0.72 percent.

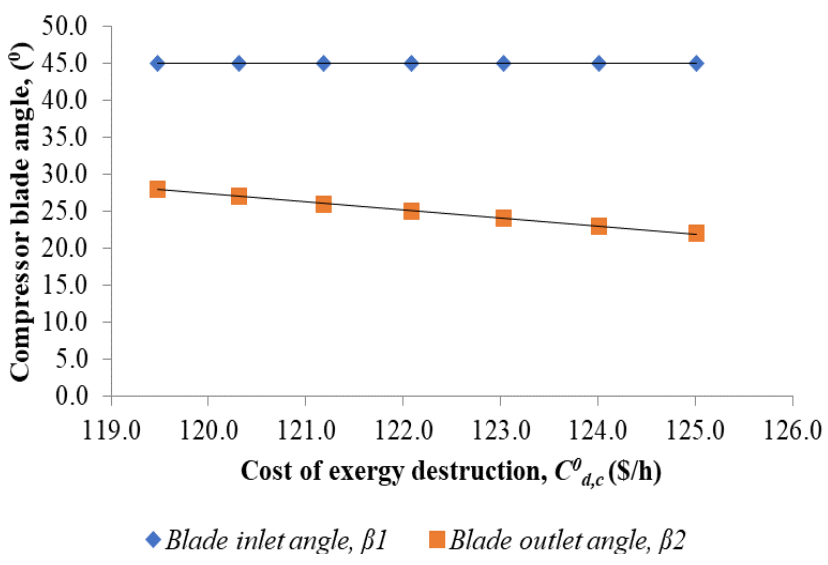

Fig 14: Graph of Compressor Blade Angle Vs Cost of Exergy Destruction

As the pressure ratio rises due to a decrease in $\beta_{2}$, the average cost per unit of exergy input rises. The average cost of exergy input to the system, as well as the cost of additional work, tends to rise as the pressure ratio rises. The average cost per unit of exergy input vs. the rotor blade angle is shown in Figure 15. When $\beta_{2}$ was reduced by $1^{0}$, the average cost per unit exergy input increased by 0.64 percent.

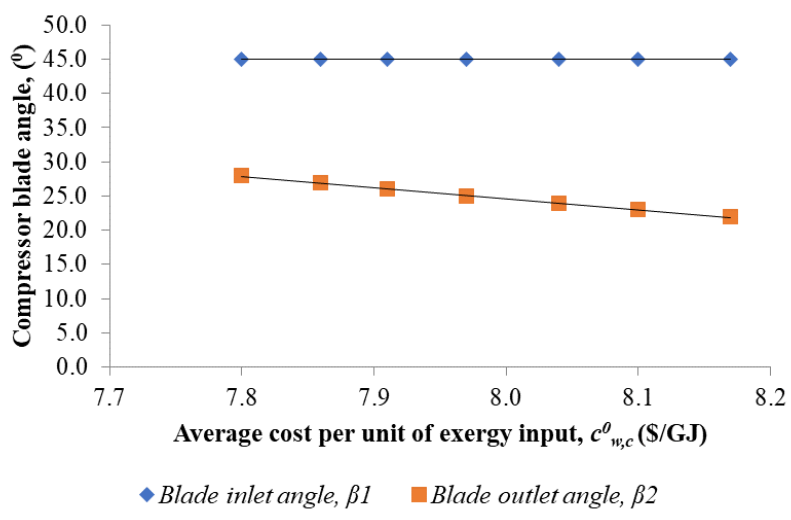

Fig 15: Graph of Compressor Blade Angle Vs Average Cost Per Unit of Exergy Input 
ISSN: 2277-3754

ISO 9001:2008 Certified

International Journal of Engineering and Innovative Technology (IJEIT)

Volume 11, Issue 5, November 2021

A graph of rotor blade angle against average cost per unit exergy output is shown in Figure 16. The average cost per unit of exergy output rises as $\beta_{2}$ decreases. The cost of the unit product rises with pressure ratio due to higher investment costs and exergy destruction at higher turbine inlet temperatures, according to [17]. Figure 16 shows that as $\beta_{2}$ decreased by $1^{0}$, the average cost of unit exergy output increased by 1.32 percent.

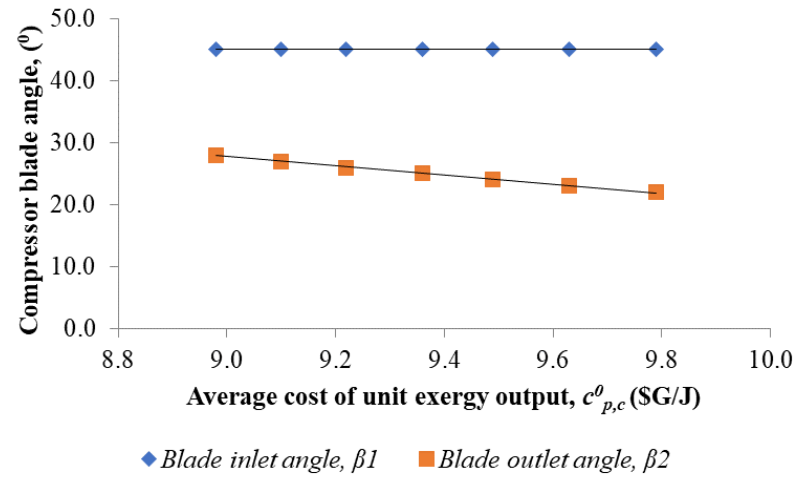

Fig 16: Graph of Compressor Blade Angles Vs Average Cost per Unit of Exergy Output

A graph of rotor blade angle against relative cost difference is shown in Figure 17. Because of the pressure ratio and exergy destruction, the relative cost difference increases as $\beta_{2}$ decrease. The comparison with related data is comparable with that published by [4], who found that as $\beta_{2}$ decreases, the pressure near the tongue of an impeller increases. Figure 9 shows that as $\beta_{2}$ reduced by $1^{0}$, the relative cost difference increased by 4.89 percent.

A graph of rotor blade angle vs exergo-economic factor is shown in Figure 18. As $\beta_{2}$ drops, the exergo-economic factor rises due to higher total capital investment, operating and maintenance cost, pressure ratio, and cost of exergy destruction. Exergo-economic factor was shown to be influenced by the overall cost of investment and the cost of exergy destruction, according to [5]. As $\beta_{2}$ decreased by $1^{0}$, the exergo-economic factor increased by 3.059 percent, as illustrated in Figure 10.

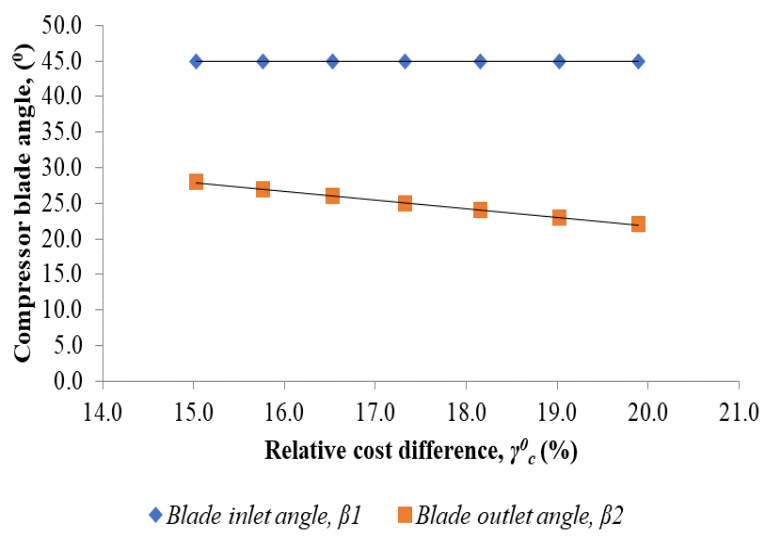

Fig 17: Graph of Compressor Blade Angle Vs Relative Cost Difference

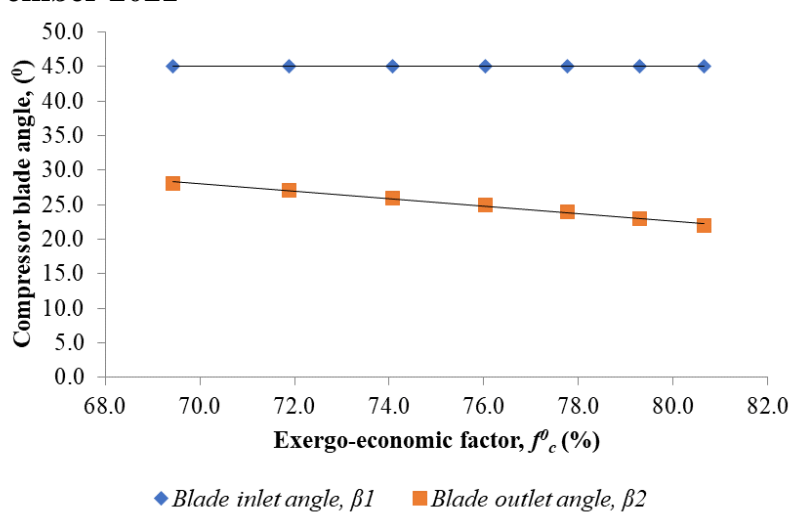

Fig 18: Graph of Compressor Blade Angle Vs Exergo-economic Factor

\section{IV.CONCLUSION}

The effects of compressor rotor blade profile change on the thermo-economic performance of axial compressor of a gas turbine was carried out in this study. The pressure ratio increases as $\beta_{1}$ increases and drops as $\beta_{2}$ increases. As $\beta_{1}$ increased, the pressure ratio decreased due to increased deflection, diffusion, and a high rate of entropy generation. The thermo-economic models developed in this work revealed that as $\beta_{1}$ increases, the equipment cost, annualized cost, total investment, operation, and maintenance cost increase and decrease. This is because pressure ratio rises with $\beta_{1}$ and drops with $\beta_{2}$. Cost of exergy destruction decreases with decrease in $\beta_{1}$ and increases as $\beta_{2}$ decreases. This was because of lowering of entropy generation during the compression process at constant $\beta_{2}$ with increase in $\beta_{1}$. Cost of exergy destruction was reduced by 2.62 percent as $\beta_{1}$ decreased by $1^{0}$. The average cost of unit exergy input increases as the rotor blade outlet angle decreases and decreases as the blade inlet angle increases. The average cost per unit of exergy output rises as $\beta_{2}$ decreases. The study also revealed that the relative cost difference increases with increase in $\beta_{1}$ and increases with decrease in $\beta_{2}$. Whereas the exergoeconomic factor increases as $\beta_{1}$ increases, it decreases as $\beta_{2}$ increases. The relative cost difference is the cost increase between the average unit cost of exergy input and output, which is influenced by the cost of exergy destruction. According to the values of the relative cost difference and the exergo-economic factor, $\beta_{1}$ has a stronger influence on thermo-economic performance than the blade outlet angle. A high relative cost difference indicates a high rate of exergy destruction, which can be improved by reducing $\beta_{1}$ of the compressor rotor blades.

\section{REFERENCES}

[1] Abdulrahman, A., Pericles, P. \& Nawaf, A., "Exergetic, Exergo-economic and Exergo environmental Analysis of 
ISSN: 2277-3754

ISO 9001:2008 Certified

International Journal of Engineering and Innovative Technology (IJEIT)

Volume 11, Issue 5, November 2021

Intercooled Gas Turbine Engine", 52 ${ }^{\text {nd }}$ propulsion energy Conference, Salt Lake City, Utah, USA. PP: 11-25, 2016.

[2] Ameri, M., Ahmadi, P., \& Hamadi, A., "Energy, Exergy and Exergo-economic Analysis: A Case Study", International journal of Energy Research, 38(5), PP: 499-512, 2009.

[3] Bejan, A., Tsatsaronis G., \& Moran M., "Thermal Design and Optimization", John Wiley \& Sons, Inc. USA, PP: 1-32, 1996.

[4] Ding, H., Li, Z, Gong X. \& Li, M., "The Influence of Blade Outlet Angle on the Performance of Centrifugal Pump with High Specific Speed", International Journal of Rapid Communication in Vacuum, Plasma, Surface, and Material Science, 159(2), PP: 239-246, 2019.

[5] Eke, M.N., Onyejekwe, D.C., Iloeje. O.C., Ezekwe, C.I., \& Akpan, P.U., "Energy and Exergy Analysis of a 220MW Power Plant", Nigerian Journal of Technology, 37(1), PP: $115-123,2018$

[6] Franco, J.S., Jesunio, T.T., \& Joao, R.B., "Gas Turbine Transient Performance Study for Axial Compressor Operation Characteristics", Nineteenth International Congress of Mechanical Engineering, November 5-9, 2007, PP: 1-8, 2007.

[7] Gorji-Bandpy, M., Goodarzian, H., \& Biglari, M., "The CostEffective Analysis of a Gas Turbine Power Plant", Energy Sources Part B: Economic, Planning and Policy, 4, PP: 348$358,2010$.

[8] Hart, H.I., "Gas Turbine Operation Experience in the Niger Delta Area of Nigeria", The Nigerian Engineer, 27(3), PP: 29-40, 1992.

[9] Hart, H.I., "On Air Pollution and Gas Turbine Performance", Technical Transactions, 36(4), PP: 64-71, 2001.

[10] Huadong, Y. \& Hong, X., "The Effects of Surface Roughness on Thermodynamic Performance Parameter of Axial Flow Compressor", Research Journal of Applied Sciences, Engineering and Technology, 5(18), PP: 4458-4463, 2013.

[11] Igbong, D.I. \& Fakorede D.O, "Exergoeconomic Analysis of a 100MW Unit GE Frame 9 Gas Turbine Plant Ughelli, Nigeria”, International Journal of Engineering and Technology, 4(8), PP: 463-468, 2014.

[12] Jain, V. \& Lin, C.X., "Numerical Modeling of ThreeDimensional Compressible Gas Flow in Microchanels", Journal of Micromechanics and Micro engineering, 16, PP: 292-302, 2006

[13] Jamnani, M.B. \& Kardger, A., "Energy-Exergy Performance Assessment with Optimization Guidance for the Components of the 396MW Combined Cycle Power Plant", Journal of Energy, Science and Technology, 8(10), PP: 3561-3574, 2020 .

[14] Kaviri, G. A. \& Jaafa M.N.M., "Effects of Air Compressor Isentropic Efficiency on Cost, Energy, Exergy and Efficiencies of CCPP", $7^{\text {th }}$ International Conference on Advances in Thermo fluid, Kuala Lumpur, Malaysia. PP: 1-5, 2015 .

[15] Lazzaretto, A., \& Tsatsaronis, G., "SPECO: A Systematic and General Methodology for Calculating Efficiencies and Costs in Thermal Systems". Energy, 32, PP: 1257-1289, 2006.
[16] Massardo, A.F. \& Scialo, M, "Thermo economic Analysis of Gas Turbine Based Cycles", Journal of Engineering Gas Turbines and Power, 122(4), PP: 664-671, 2000.

[17] Mondal, P. \& Ghosh S., "Integrated Biomass Gasification Combined Cycle Plant for Small Scale Generation: Part B Exergetic and Exergo-economic Analysis", Journal of Material Science and Engineering, 377(1), PP: 1-6, 2018.

[18] Mukesh, G. \& Raj, K., "Thermo-economic Optimization of a Boiler Used in A Coal Fired Thermal Power Plant Based on Hot Air Temperature", International Journal of Recent advances in Mechanical Engineering (IJMECH) 4(2), PP: 3944,2015 .

[19] Oyedepo, S.O., Richard, O.F., Samuel, S.A \& Mahbub, A., "Thermo-economic and Thermo-environomic Modeling and Analysis of Selected Gas Turbine Power Plants in Nigeria", Journal of Science and Engineering, 3(5), PP: 423-442, 2015.

[20] Oyedepo, S.O., Fangbele, R.O., \& Adefila, S.S., “Assessment of Performance Indices of Selected Gas Turbine Power Plants in Nigeria", Journal of Energy, Science and Engineering, 3(3), PP: 239-256, 2015.

[21] Raja, A. K., Srivastava, A. P., \& Dwivedi, M., "Power Plant Engineering", Delhi: New Age International Publications, PP: $23-46,2006$

[22] Reddy, B.V. \& Mohamed K.I., "Exergy Analysis of a Natural Gas Fired Combined Cycle Power Generation", International Journal of Exergy, 4(2), PP: 181-194, 2007.

[23] Valencia, G., Duarte, J. \& Cesar, I., "Thermo economic Analysis of Different Exhaust Waste-Heat Recovery Systems for Natural Engines Based on ORC", Journal of Applied Sciences, 9(18), PP: 1-20, 2019.

[24] Valero, A., Lozano, M.A., Serra, L. \& Torres, C., "The CGAM Problem”, Energy, 19(3), PP: 365-381, 1994.

\section{NOMENCLATURE}

\section{Symbols}

E Exergy $(\mathrm{kJ} / \mathrm{kg})$

$T \quad$ Temperature $(\mathrm{K})$

$s^{0} \quad$ Specific entropy $(\mathrm{kJ} / \mathrm{kg} \mathrm{K})$

$h$ Specific enthalpy $(\mathrm{kJ} / \mathrm{kg})$

$m_{a} \quad$ Mass flow rate of air $\quad(\mathrm{kg} / \mathrm{s})$

$R_{a} \quad$ Gas constant for air $(\mathrm{kJ} / \mathrm{kg} \mathrm{K})$

$I_{c}^{0} \quad$ Exergy destroyed $(\mathrm{kJ} / \mathrm{kg})$

$W_{N E T}$ Power output $(\mathrm{kJ} / \mathrm{kg})$

Z Height (m)

$P \quad$ Pressure (bar)

$r_{p} \quad$ Pressure ratio (measurements)

$r_{p, c}^{0} \quad$ Pressure ratio (blade angle)

$U$ Peripheral blade velocity $(\mathrm{m} / \mathrm{s})$ 
ISSN: 2277-3754

ISO 9001:2008 Certified

International Journal of Engineering and Innovative Technology (IJEIT)

Volume 11, Issue 5, November 2021

$V_{a} \quad$ Air absolute velocity $(\mathrm{m} / \mathrm{s})$

$V_{w} \quad$ Whirl velocity $(\mathrm{m} / \mathrm{s})$

$V \quad$ Rotor blade velocity $(\mathrm{m} / \mathrm{s})$

$N_{s} \quad$ Number of compressor stages

$P E C_{c}^{0}$ Equipment cost (\$)

$S V_{c}^{0} \quad$ Salvage value

$P W$ Present worth

$C R F$ Capital recovery factor

$C_{c}^{0} \quad$ Annualized cost (\$/yr)

$Z_{c}^{0} \quad$ Total capital investment, operation, and maintenance Cost $(\$ / \mathrm{h})$

$\boldsymbol{n}$ Total operating period (yr)

$N \quad$ Number of running hours (h)

$\gamma_{c}^{0} \quad$ Relative cost difference

$f_{c}^{0} \quad$ Exergo-economic factor

\section{Greek Symbols}

$\phi \quad$ Maintenance factor

$\gamma \quad$ Ratio of specific heats

$\alpha \quad$ Air angle $\left({ }^{0}\right)$

$\beta \quad$ Blade angle $\left({ }^{0}\right)$

$\varepsilon_{c} \quad$ Exergetic efficiency

$\eta_{i s} \quad$ Compressor isentropic efficiency

\section{Subscript}

1 Compressor inlet condition

2 Compressor outlet and combustion chamber inlet condition

3 Combustion chamber outlet and turbine inlet condition

4 Turbine outlet condition

in Inflows

out Outflows

$w, c \quad$ Input to compressor

$p, c \quad$ Output from compressor

$p, c c$ Output from combustion chamber

$p, t \quad$ Output from turbine

d Destruction

ref Environmental condition

act Actual

$s t \quad$ Stage

Abbreviations and Notations

FOD Foreign object damage

$\mathrm{Kg} \quad$ Kilogram

LHV Low heating value

LNG Liquefied Natural Gas

MATLAB Matrix laboratory

MW Mega watt

SPECO Specific exergy costing
Appendix A: Summary of Average Operating Data for 180MW ALSTOM GT13-E2 Gas Turbine Power Plant and Compressor Blade parameters (Source: FIPL, 2018)

Parameter Value Unit

Compressor inlet temperature, $T_{1}$ 27.73 ${ }^{0} \mathrm{C}$

Compressor inlet pressure, $P_{l}$ 1.008 Bar

Compressor outlet temperature, $T_{2}$ $389.36 \quad{ }^{0} \mathrm{C}$

Compressor outlet pressure, $P_{2}$

11.75 Bar

Fuel gas (natural gas) mass flow rate, $m_{f}$

$7.60 \mathrm{~kg} / \mathrm{s}$

Turbine inlet temperature, $T_{3}$ $1040.65 \quad{ }^{0} C$

Turbine outlet temperature, $T_{4}$ $508.38 \quad{ }^{0} \mathrm{C}$

Power output

116.38

MW

Blade inlet angle

Blade outlet angle

Air inlet velocity

200

$\mathrm{m} / \mathrm{s}$ 